\title{
Bringing Complexity into Social Analysis: Three Principles from Emergence Benyamin Lichtenstein
}

\section{Benyamin Lichtenstein* \\ Department of Management and Marketing, University of Massachusetts, Boston, USA}

Submission: May 30, 2018; Published: September 26, 2018

*Corresponding author: Benyamin Lichtenstein, Department of Management and Marketing, University of Massachusetts, Boston, USA, Email: benyamin.bml@gmail.com

\begin{abstract}
Systems are increasingly complex, and traditional theories and constructs don't consider the dynamics of the social world. Through 60+ published papers exploring these complexity dynamics, I have summarized the differences into three core insights: Non-linearity, Interdependence, and Emergence. This brief review summarizes how to use each of these insights, and how they can reveal dynamics that are important but mostly hidden.
\end{abstract}

Keywords: Social; Deterministic; Dynamics; Genetic; Bricolage; Tremendous; Traditional; Co-Creative; Emphasizes; Discipline; Trigger; Leverage

\section{Introduction}

A growing set of models and theories are integrating the dynamics of complex systems into their analyses. These approaches diverge from the classic, deterministic methods that have dominated the social sciences since the 1960s. An exemplar of these new models is Effectuation [1]. which emphasizes the resources an entrepreneur has, and builds on those step by step, until a unique outcome comes into focus. Such outcomes are not predictable but may be far beyond what was originally expected. Another exemplar is computational complexity science; all the models affiliated with the Santa Fe Institute [2,3]. These include NK Landscapes [4]. Complex Adaptive Systems [5]. Genetic Algorithms and other systems [6]. which have helped reveal the interdependence of agents in simulated environments. A more recent example is Imagineering, a book in press by which examines a special emergent state called Collective Creativity, in which an entire group together generates a new artistic expression or concept [7]. notion of Bricolage also draws on this idea, where the emergence of the system or entity is a kind of open-ended assemblage, with outcomes that may not be foreseen.

These are paralleled in my work on Generative Emergence $[8,9]$. which explores the drivers of emergence and compares them with others. My study of emergence started with systems scientists like [10-13]. over 35 years I have sought the core characteristics of emergence in social systems. Here I present the three that are most central.

\section{Non-Linearity}

In our training as social scientists, one core assumption is that the world has linear causality: A unit of action should lead to a corresponding unit of outcome. However, it turns out that our world is filled with non-linear systems, in which certain interactions have much higher impact in the system than do others [14]. This can be visualized using the " $80 / 20$ rule": Eighty percent of the system is 'ruled' by just $20 \%$ of the agents, i.e. a small percentage of the system has the greatest effect. Thus, the influence of the top $20 \%$-really of the top $1 \%$-is amplified to a remarkable degree.

The assumption of non-linearity leads to other changes in our theorizing. For example, non-linear systems have leverage points: Specific places where an intervention has a dramatically increased outcome. Here, the system's non-linearity is strongly expressed. Although rare, leverage points have tremendous impact. Another expression of non-linearity is in trigger points or thresholds of emergence; these have been shown by [15-19]. amongst others. Once you hit a threshold of change, the system enacts a rapid creation of new order.

\section{Agent Interdependence}

Another key shift in these new dynamic models, is the interdependence across agents; the ways in which each one's influence is felt by the other, such that our interactions are deeply intertwined. In contrast, traditional social science emphasized the independence of agents, such that a researcher could examine a system without really influencing it. However, in dynamic and natural systems, an agent's identity-as part of a group or community or network-is created by the presence of all the other agents in the system. Agents are co-creative, coemergent, co-dependent on each other for their existence. 
This new assumption of interdependence has its own implications that can be brought into our analysis. To begin it implies a greater scope of responsibility: All agents are in some way responsible for the outcome of a system. It also leads to a highly inclusive sense of voice: All agents in the system should be involved in its development. Moreover, when interdependence is taken seriously in relationships, it can help resolve imbalances of power. Finally, like with non-linearity, linear causality is called into question, for if two agents are fully interdependent their actions depend on each other, making it hard to render direct causality. This alone can open many new pathways for action and engagement.

\section{Emergence: Something New is Added}

In the interaction of non-linearity and interdependence is emergence; where something new is created. Numerous scholars have explored the dynamics of emergence in social systems, including [19,23-32].

Even with all those insights, emergence researchers are still uncertain about how to capture emergence; how to 'measure' its synergy if you will. One useful metric is capacity: The emergent has greater capacity to achieve its goals (outcomes). This can be emotional as much as physical; the feeling of being in a community-linked together through shared values, beliefs, preferences, resources. Informally one can relate this to cheering for your home team, or to the commitment you have for a core group or community.

My claim here is that we must include this added energy of emergence into our analysis and description of outcomes. It may not be simple to do, as this may be expressed at a different level of analysis or require a complementary discipline. But it is powerful to assess emergence, for the more tangible it becomes the more likely it can be reproduced.

\section{Summary}

Formally, integrating the dynamics of complex systems into our social analysis is not simple, especially since it means changing underlying assumptions that have guided virtually all our learning and practice. Yet, these three moves can make powerful change in the right direction. Non-linearity refers to amplifications of influence that are inherent in many systems. Interdependence refers to a 'mutual causality' across agents, which also increases their influence. Finally, emergence is an outcome increasingly understood, which can and should be captured through some subtle metric or experience. Together, these three provide a framework for bringing in the dynamics and complexity of our world; they are tools that can be used to break out of the straight-jacket of normal science and thrust us into the $21^{\text {st }}$ century of complex systems.

\section{References}

1. Sarasvathy S (2001) Causation and Effectuation: Toward a theoretical shift from economic inevitability to entrepreneurial contingency. Academy of Management Review 26(2): 243-263.
2. Waldrop M (1992) Complexity, NY: Touchstone/Simon \& Schuster, New York, USA.

3. Cowan G, Pines D, Meltzer D (Eds.), (1994) Complexity: Metaphors, Models, and Reality (Vol. Proceedings, \#11). Addison-Wesley, New York, USA. s

4. Kauffman S (1993) The Origins of Order. NY: Oxford University Press, New York, USA.

5. Holland J (1995) Hidden Order

6. Anderson P, Arrow K, \& Pines D (1988) Thse Economy as an Evolving Complex System. Redwood City: Addison-Wesley, California, USA.

7. Garud R, Karnoe P(2003) Bricolage versus breakthrough: distributed and embedded agency in technology entrepreneurship. Research Policy 32(2): 277-301.

8. Lichtenstein B (2014) Generative Emergence: A New Discipline of Organizational, Entrepreneurial, and Social Innovation. City: Oxford University Press, New York, USA

9. Lichtenstein B (2016) Emergence and emergents in entrepreneurship: Complexity science insights into new venture creation. Entrepreneurship Research Journal 6(1): 43-52.

10. Bateson G (1972) Steps to an Ecology of Mind. NY: Ballantine Books, New York, USA.

11. Jantsch E (1980) The Self-Organizing Universe. NY: Pergamon Press, New York, USA.

12. Prigogine I \& Stengers I (1984) Order out of Chaos. NY: Bantam Books, New York, USA.

13. Laszlo E (1987) Evolution - The Grand Synthesis. MA: Shambhalla, Boston, USA.

14. McKelvey B \& Andriani P (2005) Why Gaussian statistics are mostly wrong for strategic organization. Strategic Organization 3(2): 219-228.

15. Smith C \& Gemmill G (1991) Self-Organization in small groups: A study of group effectivenss within non-equilibrium conditions. Human Relations 44: 697-716.

16. Nonaka I (1994) A dynamic theory of organizational knowledge creation. Organization Science 5(1): 14-37.

17. Lichtenstein B (2000) Self-organized transitions: A pattern amid the "chaos" of transformative change. Academy of Management Executive $14(4), 128-141$

18. Chiles T, Meyer A ,Hench T (2004) Organizational emergence: The origin and transformation of Branson, Missouri's Musical Theaters. Organization Science 15(5): 499-520.

19. Plowman DA, Baker L, Beck T, Kulkarni M, Solansky S, et al. (2007) Radical Change Accidentally: The Emergence and Amplification of Small Change. Academy of Management Journal 50(3): 515-543.

20. Gartner W (1993) Words lead to deeds: Towards an organizational emergence vocabulary. Journal of Business Venturing 8(3):231-239.

21. Crutchfield J (1994) Is anything ever new? Considering emergence. In G Cowan, D Pines \& D Meltzer (Eds.), Complexity: Metaphors, models, and Realty, Reading, MA: Addison-Wesley, pp. 479-497.

22. Bedau M (1997) Weak emergence. Philosophical Perspectives 11:375 399.

23. Guastello S (1998) Self-organization and leadership emergence. Nonlinear Dynamics, Psychology, and Life Sciences 2(4): 301-316.

24. MacIntosh R, MacLean D (1999) Conditioned emergence: A dissipative structures approach to transformation. Strategic Management Journal 20(4): 297-316.

25. Goldstein J (2000) Emergence: A concept amid a thicket of conceptual snares. Emergence 2(1): 5-22. 


\section{Annals of Social Sciences \& Management studies}

26. McKelvey B (2001) What is complexity science? It is really order creation science. Emergence 3(1): 137-157.

27. Corning P (2002) The re-emergence of 'emergence': A vernerable concept in search of a theory. Complexity 7(6): 18-30.

28. Sawyer K (2004) The mechanisms of emergence. Philosophy of the Social Sciences 34(2): 260-282.

29. Sawyer K (2005) Social Emergence: Societies as Complex Systems. NY: Cambridge University Press, New York.
30. Garud R, Kumaraswamy A, Sambamurthy V (2006) Emergent by design: Performance and transformation at Infosys Technologies. Organization Science 17(2): 277-286.

31. Garud, R, Simpson B Langley A \& Tsoukas H (2015) The Emergence of Novelty in Organizations. UK: Oxford University Press Oxford, England.

32. McKelvey B (2004) Toward a complexity science of entrepreneurship Journal of Business Venturing 19(3): 313-341.

Your next submission with Juniper Publishers
will reach you the below assets
- Quality Editorial service
- Swift Peer Review
- Reprints availability
- E-prints Service
- Manuscript Podcast for convenient understanding
- Global attainment for your research
- Manuscript accessibility in different formats
( Pdf, E-pub, Full Text, Audio)
- Unceasing customer service
Track the below URL for one-step submission
https://juniperpublishers.com/online-submission.php

